\title{
BMJ Open Infant's sex, birth control policy and postpartum well-being: a prospective cohort study in Shanghai, China
}

\author{
Jing Hua, ${ }^{1}$ Liping Zhu, ${ }^{2}$ Wenchong Du, ${ }^{3}$ Li Du, ${ }^{2}$ Ting Luo, ${ }^{4}$ Zhuochun Wu ${ }^{4}$
}

To cite: Hua J, Zhu L, Du W, et al. Infant's sex, birth control policy and postpartum well-being: a prospective cohort study in Shanghai, China. BMJ Open 2016;6:e012207. doi:10.1136/bmjopen-2016012207

- Prepublication history for this paper is available online To view these files please visit the journal online (http://dx.doi.org/10.1136/ bmjopen-2016-012207)

Received 8 April 2016 Revised 30 July 2016 Accepted 13 September 2016

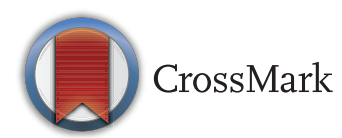

\footnotetext{
${ }^{1}$ Department of Shanghai First Maternity and Infant Hospital, The Women and Children's Health Care, Tongji University School of Medicine, Shanghai, China ${ }^{2}$ The Research Office of Shanghai Maternity and Child Health Care Center, Shanghai, China

${ }^{3}$ Psychology Division, Nottingham Trent University, Nottingham, UK

${ }^{4}$ Department of Public health School, Health Statistics and Social Medicine, Fudan University, Shanghai, China

Co-correspondence to Professor Liping Zhu; shzhuliping@163.com and Dr Jing Hua; szhuaj@hotmail.com
}

\section{ABSTRACT}

Objectives: The majority of Chinese families were under either one-child or two-child birth control policy status from 2001 to 2015 . We explore the association between an infant's sex and the mother's postpartum well-being, which may be moderated by birth control policy status in China.

Setting and participants: We conducted a prospective cohort study in Shanghai City, one of the largest cities in China. A total number of 1730 childbearing women from eight obstetric hospitals across Shanghai were included in the study at baseline, with 1503 women completing the survey 7 days postpartum in 2013.

Measures: The General Well-Being Schedule (GWBS) was used to assess maternal well-being at baseline and follow-up investigation in the study. The women's demographic, clinical characteristics, and well-being were measured at baseline. Maternal satisfaction and postpartum well-being were assessed in the follow-up survey.

Results: Multivariable linear regression analyses showed that women who gave birth to male infants were positively associated with the total score of maternal well-being, when the participating hospitals, maternal well-being at baseline, sociodemographic characteristics, and maternal and infant health outcomes were added to the adjustments $(\beta=1.462$, $p<0.05)$. The association disappeared when the two-child policy status was added to the adjustments ( $p>0.05)$. The results of a multiple logistic regression model showed that having a male infant was a risk factor of 'severe distress' $(0 R=1.607, p<0.05)$, which was moderated by the two-child policy status ( $p>0.05$ ).

Conclusions: Our results emphasise the importance of conducting interventions to increase maternal general well-being, especially for those with a female infant in a society such as China where preference is for a son, and enhance the necessity of sustainability of a newly relaxed two-child policy which allows more couples to have a second child in China.

\section{INTRODUCTION}

Developing a sense of well-being and achieving competence in the maternal role are considered as critical components of
Strengths and limitations of this study

- The results of our study have important clinical implications regarding the effect of birth control policy and gender preference on postnatal maternal mental health.

- Our study is the first to provide direct evidence on how relaxation of a birth control policy could positively increase a new mother's mental health status.

- We recruited the participants at 29-30 weeks of gestation from among low-risk primiparous women in order to avoid other possible confounders such as severe complications during pregnancy and the first child's sex which may influence a multiparous woman's well-being.

- Selection bias may exist in our study as $1.5 \%$ of the women refused to take part at baseline and $13.1 \%$ were missing or excluded from the follow-up investigation. Women with a higher level of psychological well-being during their pregnancy may have been more likely to take part in our study and complete the follow-up investigation.

maternal adaptation during the transition to motherhood. ${ }^{1}$ Maternal psychology is also known to impact a child's physical ${ }^{2}$ and mental health. ${ }^{3}{ }^{4}$ However, previous studies in China have shown a significant difference in maternal postpartum mental health when comparing different genders of newborn infants. ${ }^{56}$ Women who gave birth to a female infant were at a higher risk of postpartum depression after adjusting for maternal age, education level, family income, living condition, gravidity, number of prenatal care visits, and mode of delivery. Fathers of male infants had significantly higher parenting satisfaction scores than fathers of female infants following the birth. ${ }^{7} 8$ This is in contrast to studies conducted in Western societies which did not find an association between fetal gender and postpartum psychology. ${ }^{9}$

The strong preference for boys is well known in Chinese culture because boys will 
carry their family lineage and may earn more income for the family and society. ${ }^{10}$ The gender preference has become a subject of considerable discussion since the one-child family policy was implemented in $1974 .{ }^{10}{ }^{11}$ The one-child family policy in China has been suggested as leading to a stronger preference for males, ${ }^{12} 13$ which may affect maternal psychological wellbeing when the male preference could not be met. Studies have shown that disappointment over the baby's gender is a significant risk factor for postnatal depression. ${ }^{14}$ Under the one-child policy in China, the gender of newborn babies plays an important role in the mother's postnatal mental health status, because families do not have a second chance to have another child if they are not happy with the gender of the newborn baby. Unfortunately, there are limited studies exploring these relationships in Chinese culture.

In 2001, the Chinese government loosened its birth control policy and allowed parents to have a second child if both parents were from a one-child family. The policy has been further relaxed and since 2016 all couples have been allowed to have two children. Therefore, the majority of Chinese families were under either one-child or two-child birth control policy status from 2001 to 2015. We conducted a prospective cohort study during 2013 in Shanghai City, one of the largest cities in China. We hypothesised that mothers with a male infant were positively associated with a higher level of postpartum wellbeing, but may be moderated by birth control policy status. The aims of the current study were: (1) to explore the association between an infant's sex and the mother's postpartum well-being including anxiety, depression, general health, positive well-being, self-control, and vitality; and (2) to examine whether the birth control policy status would moderate the association.

\section{PARTICIPANTS AND METHODS}

\section{Participants}

A prospective research design was used to collect data at two time points (baseline and follow-up). Eight obstetric hospitals were selected from eight separate districts across Shanghai by convenience sampling. The childbearing women who attended antenatal clinics in the eight selected hospitals were eligible for the study if they met the following inclusion criteria: (1) 29-30 weeks of gestation at recruitment; (2) primiparous; (3) singleton pregnancy. The exclusion criteria were: (1) personal, family-based psychiatric history; (2) presence of medical or obstetric complications (such as gestational diabetes and preeclampsia) before the final investigation; (3) fetal malformations; (4) unable to provide consent. Nineteen thousand and two childbearing women who were eligible according to the inclusion criteria were invited to take part in the study at baseline; 29 women were unable to provide informed consent or refused to complete the questionnaire. A total of 1730 childbearing women were included in the cohort, and finally 1503 women who completed the follow-up questionnaire with no missing information or fetal malformation were included in the final analysis (figure 1). There were no differences in maternal age, education level, vocation and method of payment, or in well-being level at baseline between the missing $(\mathrm{n}=227)$ and inclusion data $(\mathrm{n}=1503) \quad($ each $\mathrm{p}>0.05)$.

\section{Measurements}

The General Well-Being Schedule (GWBS) was used to assess maternal well-being at baseline (at 29-30 weeks of gestation of the recruited women) and follow-up investigation (7-14 days after birth) in the study. GWBS is an 18-item multi-dimensional scale developed by Harold Deputy and revised by Fazio Anthony, ${ }^{15}$ which has been validated in American and Asian populations. ${ }^{16-19}$ Duan ${ }^{20}$ has translated the GWBS scale into Chinese and reported its validation in China: the internal consistency (Cronbach's $\alpha$ coefficients of male and female were 0.91 and 0.95 , respectively) and construct validity (the Pearson correlation coefficients between the scores of each item and total score were from 0.65 to 0.88 ) of GWBS were reliable in a Chinese population. GWBS covers six dimensions of subjective feelings of psychological well-being: anxiety (nervousness; stress; strain; pressure; anxious, worried; upset; relaxed-tense), depression (sad; discouraged; hopeless; downhearted; blue; depressed-cheerful), general health (bothered by bodily disorders; health; concern; worry), positive well-being (good spirits; happy, satisfied; interesting daily life), selfcontrol (firm control of behaviour; emotions; afraid of losing their mind; emotionally stable; sure of self) and vitality (waking, fresh, rested; feeling tired, worn out; energy level). All items refer to the experience of participants in the previous month. Items $1-14$ are scored from 0 to 5, while items $15-18$ are scored from 0 to 10 . Items $1,3,6,7,9,11,15$, and 16 are reverse scored. The scores of each dimension were summed by their corresponding items. The total score of GWBS was summed by the scores of six dimensions. The higher scores represent greater well-being. Proposed cutoffs $(60,72)$ representing three levels of well-being are 73-110 (positive well-being), 61-72 (moderate distress), and 0-60 (severe distress).

\section{Procedure}

The survey was conducted from May to October 2013. The questionnaires were filled out by women when they attended regular antenatal health education courses in the selected hospitals. Teachers of health education courses (usually the medical practitioners from the hospitals) were trained to brief through the aim of the current study and the questionnaires to the participants. The participants were asked to fill out the questionnaire individually in half an hour at the end of the courses according to the attached illustration. The teachers collected and placed all filled questionnaires in a sealed envelope and posted all original hard copies to the 
Figure 1 Number of women who completed the baseline and follow-up investigations.

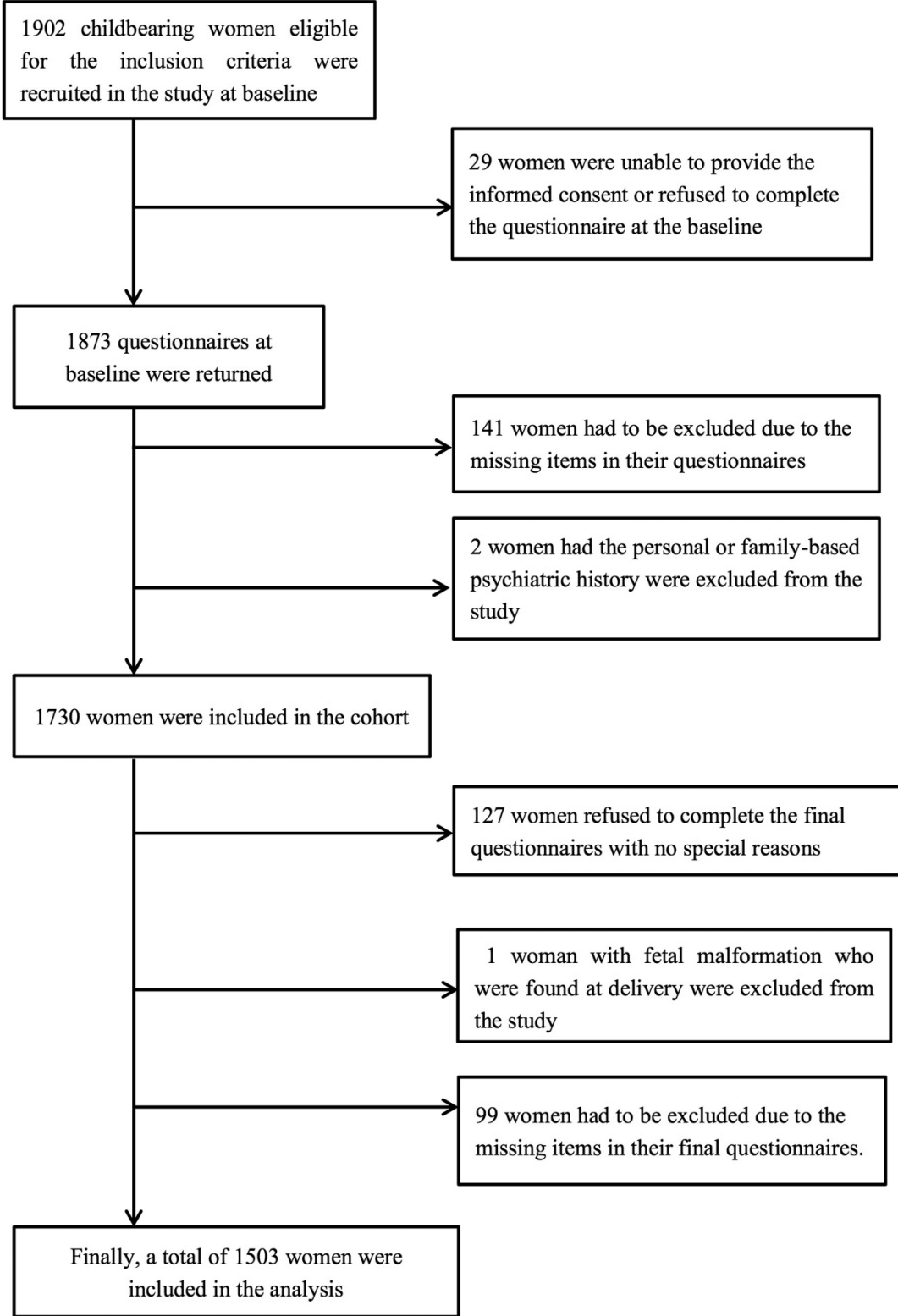

researchers. The follow-up investigation was conducted by a family interview on day 7-14 postpartum due to the Chinese tradition that a Chinese woman should remain at home for 1 month postpartum.

The study was approved by the ethics committees of the Shanghai First Maternity and Infant Hospital, Tongji University School of Medicine (\#2013-09). The study was carried out in accordance with the approved guidelines. The purposes of the study were explained to all participants verbally. All participants signed an informed consent form before enrolling in the study. The participants were advised that they could withdraw from the study at any time.

\section{Statistical analysis}

Data were analysed using the SPSS V.17.0 program. Independent-samples t-tests and $\chi^{2}$ tests were conducted to compare the two groups (women with male and female newborn infants) at baseline. Multivariable linear regression analyses were used to assess the effects of an infant's sex on delivery mode and maternal satisfaction, after adjusting for potential confounders including participating hospitals, sociodemographic characteristics, obstetric characteristics, infant's health outcome, and birth control policy status. The multi-collinearity problem was verified using the tolerance approach and the variance inflation factor. Any variable that had a tolerance value $<0.1$ and a variance inflation factor $>10$ was not included in the same regression model. ${ }^{21}$ Multiple logistic regression models ${ }^{22}$ were also used to analyse the effect of the infants' sex on the levels of maternal wellbeing when the possible potential confounders were adjusted. A p value of 0.05 was used for all tests of significance. 


\section{RESULTS}

Among all of our 1503 participants, 781 (52.0\%) gave birth to male infants (Male group) and 722 (48.0\%) gave birth to female infants (Female group). Table 1 shows the distribution of selected sociodemographic, obstetric and children's characteristics among the participants. The proportion of age, ethnicity, education, vocation, resident status, multiple gestation, and method

Table 1 Sociodemographic, obstetric and children's characteristics $(n=1503)$

\begin{tabular}{|c|c|c|c|c|}
\hline Characteristics & $\begin{array}{l}\text { Total } \\
n=1503 ;(n, \%)\end{array}$ & $\begin{array}{l}\text { Male infant } \\
n=781 ;(n, \%)\end{array}$ & $\begin{array}{l}\text { Female infant } \\
n=722 ;(n, \%)\end{array}$ & p Value \\
\hline \multicolumn{5}{|l|}{ Sociodemographic characteristics } \\
\hline \multicolumn{5}{|l|}{ Maternal age } \\
\hline$\leq 24$ & $169(11.2)$ & 95 (12.2) & 74 (10.2) & \multirow[t]{3}{*}{0.485} \\
\hline $25-34$ & 1252 (83.3) & $645(82.6)$ & $607(84.1)$ & \\
\hline$\geq 35$ & $82(5.5)$ & $41(5.2)$ & $41(5.7)$ & \\
\hline \multicolumn{5}{|l|}{ Education } \\
\hline College or university & $88(5.9)$ & $52(6.7)$ & $36(5.0)$ & \multirow[t]{3}{*}{0.054} \\
\hline Middle school & $291(19.4)$ & $165(21.1)$ & $126(17.5)$ & \\
\hline Primary school or below & $1124(74.8)$ & 564 (72.2) & $560(77.6)$ & \\
\hline \multicolumn{5}{|l|}{ Vocation } \\
\hline Company employee & $321(21.4)$ & $158(20.2)$ & $163(22.6)$ & \multirow[t]{5}{*}{0.761} \\
\hline Private owner & $106(7.1)$ & $55(7.0)$ & $51(7.1)$ & \\
\hline Technician and liberal profession & $614(40.9)$ & $318(40.7)$ & $296(41)$ & \\
\hline Unemployed & $281(18.7)$ & $153(19.6)$ & $128(17.7)$ & \\
\hline Others & $181(12.0)$ & $97(12.4)$ & $84(11.6)$ & \\
\hline \multicolumn{5}{|l|}{ Method of payment } \\
\hline Self-payment & $490(32.6)$ & $256(32.8)$ & 234 (32.4) & \multirow[t]{3}{*}{0.642} \\
\hline Government insurance & $681(45.3)$ & $346(44.3)$ & $335(46.4)$ & \\
\hline Private insurance & $332(22.1)$ & 179 (22.9) & $153(21.2)$ & \\
\hline \multicolumn{5}{|l|}{ Resident status } \\
\hline Resident women & $794(52.8)$ & $407(52.1)$ & $387(53.6)$ & \multirow[t]{2}{*}{0.564} \\
\hline Migrant women & 709 (47.2) & $374(47.9)$ & $335(46.4)$ & \\
\hline \multicolumn{5}{|l|}{ Obstetric characteristics } \\
\hline \multicolumn{5}{|l|}{ Abortion } \\
\hline 0 & $1205(80.2)$ & $617(79.0)$ & $588(81.4)$ & \multirow[t]{3}{*}{0.106} \\
\hline 1 & $221(14.7)$ & $115(14.7)$ & $106(14.7)$ & \\
\hline$\geq 2$ & $77(5.1)$ & $49(6.3)$ & $28(3.9)$ & \\
\hline \multicolumn{5}{|l|}{ Delivery mode } \\
\hline Vaginal birth & $764(50.8)$ & $399(51.1)$ & $365(50.6)$ & \multirow[t]{2}{*}{0.836} \\
\hline Caesarean section & 739 (49.2) & $382(48.9)$ & 357 (49.4) & \\
\hline \multicolumn{5}{|l|}{ Midwife-led delivery } \\
\hline No & 1069 (71.1) & $552(70.7)$ & $517(71.6)$ & \multirow[t]{2}{*}{0.692} \\
\hline Yes & $434(28.9)$ & $229(29.3)$ & 205 (28.4) & \\
\hline \multicolumn{5}{|l|}{ Infant's health outcome } \\
\hline \multicolumn{5}{|l|}{ Preterm children } \\
\hline No & 1386 (92.2) & $719(92.1)$ & $667(92.4)$ & \multirow[t]{2}{*}{0.817} \\
\hline Yes & $117(7.8)$ & $62(7.9)$ & $55(7.6)$ & \\
\hline \multicolumn{5}{|l|}{ Birth weight } \\
\hline$<2500 \mathrm{~g}$ & $24(1.6)$ & $13(1.7)$ & $11(1.5)$ & \multirow[t]{3}{*}{0.049} \\
\hline $2500-3999 \mathrm{~g}$ & $1364(90.8)$ & 699 (89.5) & $665(92.1)$ & \\
\hline$\geq 4000 \mathrm{~g}$ & $115(7.7)$ & $69(8.8)$ & $46(6.4)$ & \\
\hline Breastfeeding in first 24 hours & & & & \\
\hline No & $224(14.9)$ & $130(16.6)$ & $94(13.0)$ & 0.049 \\
\hline Yes & $1279(85.1)$ & $651(83.4)$ & $628(87.0)$ & \\
\hline Birth control policy settings & & & & \\
\hline Two-child policy status $†$ & $483(32.1)$ & $259(33.2)$ & $224(31.0)$ & 0.375 \\
\hline One-child policy status $\ddagger$ & $1020(67.9)$ & $522(66.8)$ & 498 (69.0) & \\
\hline
\end{tabular}

${ }^{*}$ Pearson $\chi^{2}$ test.

†The family was allowed to have two children if both of the parents were from one-child families under the birth control policy during the study period.

$\ddagger$ The family was allowed to have only one child if one of or both of the parents were from multi-children families under the birth control policy during the study period. 
of payment was equal between the participants in the two groups $(p>0.05)$. Birth weight differed between the participants in the two groups, and the rate of breastfeeding in the first 24 hours in the Female group was higher than in Male group, with $\mathrm{p}$ values of 0.05 (table 1). At baseline, there was no difference in the degree of maternal welling-being (non-anxiety, nondepression, positive well-being and self-control) between the two groups (each $\mathrm{p}>0.05$; table 2 ).

However, during the postpartum period, only women who gave birth to male infants were positively associated with the total score of maternal well-being when confounders were not adjusted $(\beta=1.570,95 \%$ CI 0.372 to $2.767, \mathrm{p}<0.001)$. The association remained statistically significant when the participating hospitals and maternal well-being at baseline $(\beta=1.482,95 \%$ CI 0.303 to 2.660, $\mathrm{p}<0.001), \quad$ sociodemographic characteristics $(\beta=1.526,95 \%$ CI 0.341 to $2.710, p<0.001)$, obstetric characteristics $(\beta=1.484,95 \%$ CI 0.303 to 2.665 , $\mathrm{p}=0.014)$, and infant's health outcome $(\beta=1.474,95 \%$ CI 0.293 to $2.656, \mathrm{p}=0.015$ ) were added to the adjustments. However, the association was not statistically significant when the two-child policy status (one-child status vs twochild) was added to the adjustments (1.497, -0.001 to 2.990, $\mathrm{p}=0.051$; table 3).

Similarly, the sex of the infant was also related to the score of subscale of positive well-being when not adjusting for $(\beta=0.274,0.050$ to $0.499, p<0.001)$ or adjusting for the hospitals and maternal well-being at baseline ( $\beta=0.273,95 \%$ CI 0.048 to $0.497, p<0.001)$, and when the sociodemographic characteristics $(\beta=0.303,95 \%$ CI 0.079 to $0.528, \mathrm{p}=0.008)$, obstetric characteristics $(\beta=0.297,95 \%$ CI 0.072 to $0.522, p=0.010)$, and infant's health outcome $(\beta=0.295,95 \%$ CI 0.070 to 0.521 , $\mathrm{p}=0.010$ ) were added to the adjustments. However, the positive association disappeared when the two-child birth control policy was added to the adjustments ( $\beta=0.230,95 \%$ CI -0.048 to $0.508, p=0.104$; table 3 ).

We also found a lower depression level in women who gave birth to male infants when we did not adjust for any potential confounders ( $\beta=1.339,95 \%$ CI 1.051 to 1.626 , $\mathrm{p}<0.001)$. These associations remained when the hospitals and maternal well-being at baseline $(\beta=1.335$, $95 \%$ CI 1.050 to $1.621, \mathrm{p}<0.001)$, sociodemographic characteristics $(\beta=1.333,95 \%$ CI 1.046 to $1.620, p<0.001)$, obstetric characteristics $(\beta=1.323,95 \%$ CI 1.036 to 1.610 , $\mathrm{p}<0.001)$, infant's health outcome $(\beta=1.321,95 \%$ CI 1.033 to $1.608, \mathrm{p}<0.001)$ and two-child policy status $(\beta=1.341,95 \%$ CI 0.990 to $1.692, p<0.001)$ were added to the adjustments (table 3). Additionally, the total score of GWBS was categorised into three levels (severe distress, moderate distress, and positive well-being). The results showed that women who gave birth to male infants were only associated with the level of positive well-being (adjusted OR (aOR) 1.607, 95\% CI 1.034 to 2.499, $\mathrm{p}=0.035)$ when compared with the level of positive well-being after adjustment for hospitals and maternal well-being at baseline, sociodemographic characteristics, obstetric characteristics, and infant's health outcome. However, the association disappeared when two-child policy status was added into the adjustments (aOR 1.240, 95\% CI 0.674 to 2.281, $\mathrm{p}=0.489$; table 4 ).

\section{DISCUSSION}

The present study sheds light on the influence of an infant's sex on maternal postpartum well-being. To the best of our knowledge, few studies have considered the change in birth control policy. Our study has indicated that those women who gave birth to a male infant experienced less maternal postpartum depression and enjoyed higher postpartum well-being. However, the positive association between infant gender and postpartum well-being could be moderated by the two-child birth control policy status.

In our study, the distribution of demographic characteristics, obstetric characteristics and infant's health outcome (such as exceptionally high rates of caesarean section and breastfeeding) are consistent with the general obstetric populations in the Chinese literature. $^{5} 2324$ There was no significant difference at baseline in maternal well-being between women who gave birth to male and female infants. This may be due to the fact that, since 2002, parents have not been allowed

Table 2 Maternal well-being assessed by GWBS* at baseline $(n=1503)$

\begin{tabular}{|c|c|c|c|c|}
\hline Characteristic & $\begin{array}{l}\text { Total } \\
\mathrm{n}=1503 \text {; mean (SD) }\end{array}$ & $\begin{array}{l}\text { Male infant } \\
\mathrm{n}=781 ; \text { mean (SD) }\end{array}$ & $\begin{array}{l}\text { Female infant } \\
\mathrm{n}=722 ; \text { mean (SD) }\end{array}$ & p Value* \\
\hline Anxiety & $17.13(4.491)$ & $17.21(4.574)$ & $17.05(4.401)$ & 0.505 \\
\hline Depression & $15.22(6.055)$ & $15.25(6.04)$ & 15.19 (6.076) & 0.845 \\
\hline General health & $5.82(2.492)$ & $5.81(2.484)$ & $5.84(2.503)$ & 0.823 \\
\hline Positive well-being & 7.79 (3.335) & 7.81 (3.319) & 7.77 (3.354) & 0.791 \\
\hline Self-control & 9.30 (2.699) & 9.35 (2.715) & 9.24 (2.683) & 0.414 \\
\hline Vitality & 13.41 (4.193) & 13.47 (4.206) & $13.35(4.18)$ & 0.572 \\
\hline Total score & 68.68 (11.435) & 68.91 (11.692) & $68.44(11.154)$ & 0.427 \\
\hline
\end{tabular}

Items 1, 3, 6, 7, 9, 11, 15, and 16 are reversed scored. The lower scores represent greater distress.

${ }^{*}$ All items refer to a 1-month time frame. Items 1-14 are scored on a six-point rating scale, while items $15-18$ are scored from 0 to 10. †Two independent sample t-test.

GWBS, General Well-Being Schedule. 
Table 3 Effects of fetal sex on women's postpartum well-being ( $n=1503)$

\begin{tabular}{|c|c|c|c|c|c|c|c|c|c|}
\hline $\begin{array}{l}\text { Outcome } \\
\text { variables } †\end{array}$ & $\begin{array}{l}\text { Total } n=1503 ; \\
\text { mean (SD) }\end{array}$ & $\begin{array}{l}\text { Male infant } n=781 \text {; } \\
\text { mean (SD) }\end{array}$ & $\begin{array}{l}\text { Female infant } n=722 \\
\text { mean (SD) }\end{array}$ & $\beta \neq(95 \% \mathrm{Cl})$ & $\beta \S(95 \% \mathrm{Cl})$ & 阝耳 $(95 \% \mathrm{Cl})$ & $\mathrm{Bt \dagger}(95 \% \mathrm{Cl})$ & $\beta \neq \neq(95 \% \mathrm{Cl})$ & ß§§ (95\% Cl) \\
\hline Anxiety & $19.48(3.778)$ & $19.50(3.743)$ & $19.47(3.812)$ & $\begin{array}{l}-0.035 \\
(-0.418 \text { to } 0.347)\end{array}$ & $\begin{array}{l}-0.055 \\
(-0.433 \text { to } 0.323)\end{array}$ & $\begin{array}{l}-0.046 \\
(-0.426 \text { to } 0.335)\end{array}$ & $\begin{array}{l}-0.051 \\
(-0.431 \text { to } 0.329)\end{array}$ & $\begin{array}{l}-0.056 \\
(-0.435 \text { to } 0.323)\end{array}$ & $\begin{array}{l}-0.155 \\
(-0.620 \text { to } 0.310)\end{array}$ \\
\hline Depression & $17.24(2.916)$ & $16.54(2.868)$ & $17.88(2.811)$ & $\begin{array}{l}1.339 \\
(1.051 \text { to } 1.626)^{\star * *}\end{array}$ & $\begin{array}{l}1.335 \\
(1.050 \text { to } 1.621)^{\star \star *}\end{array}$ & $\begin{array}{l}1.333 \\
(1.046 \text { to } 1.620)^{\star \star *}\end{array}$ & $\begin{array}{l}1.323(1.036 \text { to } \\
1.610)^{\star \star \star}\end{array}$ & $\begin{array}{l}1.321(1.033 \text { to } \\
1.608)^{\star \star \star}\end{array}$ & $\begin{array}{l}1.341(0.990 \text { to } \\
1.692)^{\star \star \star}\end{array}$ \\
\hline General health & 6.19 (2.695) & $6.21(2.755)$ & 6.17 (2.639) & $\begin{array}{l}-0.038 \\
(-0.311 \text { to } 0.235)\end{array}$ & $\begin{array}{l}-0.036 \\
(-0.309 \text { to } 0.236)\end{array}$ & $\begin{array}{l}-0.028 \\
(-0.301 \text { to } 0.246)\end{array}$ & $\begin{array}{l}-0.023 \\
(-0.296 \text { to } 0.250)\end{array}$ & $\begin{array}{l}-0.026 \\
(-0.300 \text { to } 0.248)\end{array}$ & $\begin{array}{l}0.192 \\
(-0.817 \text { to } 0.571)\end{array}$ \\
\hline $\begin{array}{l}\text { Positive } \\
\text { well-being }\end{array}$ & $10.56(2.22)$ & $10.41(2.202)$ & $10.69(2.231)$ & $\begin{array}{l}0.274 \\
(0.050 \text { to } 0.499)^{\star \star \star}\end{array}$ & $\begin{array}{l}0.273(0.048 \text { to } \\
0.497)^{\star \star \star}\end{array}$ & $\begin{array}{l}0.303(0.079 \text { to } \\
0.528)^{\star}\end{array}$ & $\begin{array}{l}0.297(0.072 \text { to } \\
0.522)^{\star}\end{array}$ & $\begin{array}{l}0.295(0.070 \text { to } \\
0.521)^{*}\end{array}$ & $\begin{array}{l}0.230 \\
(-0.048 \text { to } 0.508)\end{array}$ \\
\hline Self-control & $11.98(2.159)$ & $11.98(2.167)$ & $11.98(2.153)$ & $\begin{array}{l}-0.004 \\
(-0.214 \text { to } 0.223)\end{array}$ & $\begin{array}{l}-0.003 \\
(-0.221 \text { to } 0.215)\end{array}$ & $\begin{array}{l}0.029 \\
(-0.190 \text { to } 0.247)\end{array}$ & $\begin{array}{l}0.025 \\
(-0.194 \text { to } 0.243)\end{array}$ & $\begin{array}{l}0.030 \\
(-0.189 \text { to } 0.249)\end{array}$ & $\begin{array}{l}-0.112 \\
(-0.370 \text { to } 0.146)\end{array}$ \\
\hline Vitality & $15.22(3.057)$ & $15.21(3.057)$ & $15.23(3.059)$ & $\begin{array}{l}0.025 \\
(-0.284 \text { to } 0.335)\end{array}$ & $\begin{array}{l}0.012 \\
(-0.294 \text { to } 0.319)\end{array}$ & $\begin{array}{l}0.006 \\
(-0.302 \text { to } 0.314)\end{array}$ & $\begin{array}{l}-0.009 \\
(-0.316 \text { to } 0.298)\end{array}$ & $\begin{array}{l}-0.016 \\
(-0.324 \text { to } 0.292)\end{array}$ & $\begin{array}{l}-0.116 \\
(-0.507 \text { to } 0.275)\end{array}$ \\
\hline Total score & 80.66 (11.847) & 79.85 (11.653) & $81.42(11.983)$ & $\begin{array}{l}1.570(0.372 \text { to } \\
2.767)^{\star \star \star \star}\end{array}$ & $\begin{array}{l}1.482 \\
(0.303 \text { to } 2.660)^{\star \star \star}\end{array}$ & $\begin{array}{l}1.526 \\
(0.341 \text { to } 2.710)^{\star \star \star}\end{array}$ & $\begin{array}{l}1.484 \\
(0.303 \text { to } 2.665)^{\star}\end{array}$ & $\begin{array}{l}1.474 \\
(0.293 \text { to } 2.656)^{\star}\end{array}$ & $\begin{array}{l}1.497 \\
(-0.001 \text { to } 2.990)\end{array}$ \\
\hline
\end{tabular}

The score of six dimensions and total score of GWBS.

$\ddagger$ Not adjusted for any potential confounders.

§Adjusted for hospitals and maternal well-being at baseline.

ๆAdjusted for maternal well-being at baseline and sociodemographic characteristics.

††Adjusted for maternal well-being at baseline, sociodemographic characteristics and obstetric characteristics.

¥¥Adjusted for maternal well-being at baseline, sociodemographic characteristics, obstetric characteristics and infant's health outcome.

$\S \S$ Adjusted for maternal well-being at baseline, sociodemographic characteristics, obstetric characteristics, infant's health outcome and birth control policy settings.

p<0.05, $p<0.01, \quad p<0.001$.

GWBS, General Well-Being Schedule. 


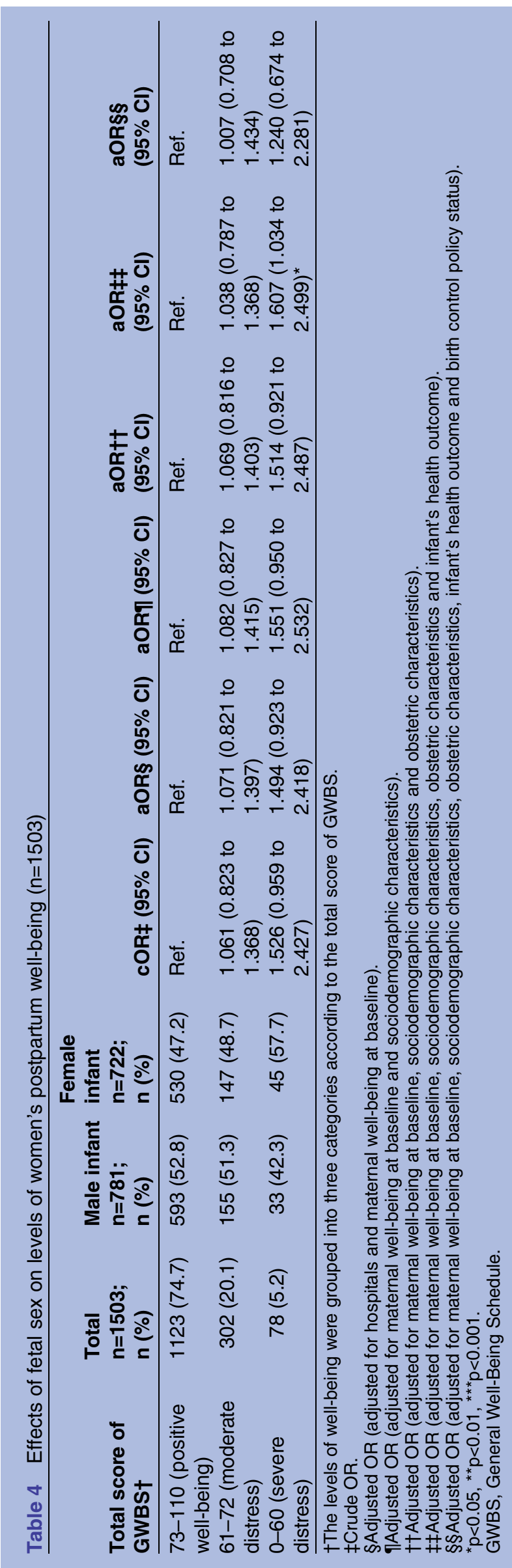

to determine the gender of the fetus before delivery in order to avoid any gender selection. ${ }^{25} 26$

Our results suggest that giving birth to a male infant was related to less postpartum depression. This finding is consistent with previous studies that showed new mothers of female infants were at increased risk of developing postpartum depression, ${ }^{5} 61214$ while new mothers of male infants experienced lower levels of depression in a society that values boys. Couples in China have a strong preference for sons due to economic and social reasons. ${ }^{27}$ For example, people usually rely on their offspring to support them in retirement because the national pension system is not very well established in China; ${ }^{28}{ }^{29}$ and sons with higher incomes will be more capable of providing financial support compared to daughters, since generally women earn less than men in China. ${ }^{30}$ More importantly, only a son's offspring would be able to carry his father's surname to continue the family lineage. The negative reaction of family members towards the birth of a female infant may subsequently affect their support of the mother, which may be a potential risk factor for postpartum depression within certain cultural groups. ${ }^{5}$

A couple's preference for a son for the sake of their, and especially the mother's, well-being seems to reinforce the sexist beliefs and practices in Chinese society at large (including urban areas such as Shanghai). However, China is undergoing a rapid socioeconomic transition. Infanticides have become very rare, and sex-selective abortion has also been reported as occurring less commonly than previously. ${ }^{31}$ The relationships between sex ratio and the preference for a son are not necessarily predictable. Moreover, the Chinese authorities have launched a range of policies to weaken these sexist beliefs and practices. From 2005, parents of a daughter in rural areas have been entitled to a pension of 7200 RMB (about US\$1075) per year. ${ }^{26}$ Also the 'Care for Girls' campaign, which provides increased educational chances for girls, has produced encouraging results, with the preference for sons declining in the 24 participating counties. ${ }^{31}$ Clearly this campaign should be widely disseminated to more areas (including the urban areas) of China.

Our results further suggest that women who gave birth to a female have a more positive postpartum general well-being and higher-level well-being status. The general and higher level of well-being which was assessed by GWBS refers to anxiety, depression, general health, positive well-being, self-control, and vitality. It is biologically plausible that the brain and body respond to stress by activating the hypothalamic-pituitary-adrenal axis and the sympathetic nervous system, preparing the body for 'fight or flight'. ${ }^{32}$ Consequently, a higher level of psychological well-being and lower depression and anxiety may result in improvements in physical fitness including general health and vitality, and enhance the level of postpartum general well-being.

Interestingly, the associations between an infant's sex and postpartum well-being disappeared when the twochild policy status was added to the adjustments, 
suggesting that families which are allowed to have more than one child may moderate the effects of the association. This could be caused by either the potential financial benefit brought by two children (either sons or daughters), or by being provided with a second chance to have a son. The Chinese government has recently scrapped its one-child family policy, allowing all couples to have two children since 2016. The policy may bring an interesting dynamic to maternal health. The effect of the preference for a son on a mother's postpartum wellbeing would be moderated by the implementation of this two-child status. However, the prevalence of older mothers is increasing because of China's two-child policy. ${ }^{33}$ Pregnancies after the age of 35 are associated with increased risks of preterm birth, gestational diabetes, placenta praevia, amniotic fluid embolism, venous thrombosis, genetic abnormalities in children, etc, ${ }^{34}$ which may inversely bring about other challenges of maternal well-being.

\section{CONCLUSIONS}

Our study reveals very important clinical implications regarding the effect of gender preference on postnatal maternal mental health. Our results emphasise the importance of conducting interventions to reduce the risk of women's postpartum depression and to enhance general well-being, especially for those with a female infant in a society which has a preference for sons, such as in China. Additionally, our study is the first to provide direct evidence of how relaxation of a birth control policy could positively increase the mental health status of new mothers. This significant change, however, will take time. The relaxation of China's birth control policy creates new challenges to maternal health, such as the increasing prevalence of older mothers; it is therefore good that the Chinese authorities are committed to improving the country's maternal healthcare services to accommodate these possible negative effects on maternal health.

There was some possible bias in our study. We recruited the participants at 29-30 weeks of gestation because the baseline investigation conducted in a different trimester may induce some potential confounders such as different health situations and maternal well-being at baseline. If we ask questions verbally in front of other family members in the postpartum interview, there would be an element of social desirability bias as their family may be upset if the newborn infants' mothers are not happy because they have had a male child. Therefore, we asked the mothers of newborn infants to fill out the questionnaires by themselves in the postpartum family interview. Moreover, we conducted the present study in low-risk primiparous women in order to avoid other possible confounders such as severe complications during pregnancy and the first child's sex which may influence a multiparous woman's well-being. ${ }^{13} 35$

Caution should be taken when generalising our results to the broad obstetric population based on a convenience sample. There may be selection bias because 29 women refused to take part in our study at baseline, and 227 were missing or excluded from the follow-up investigation (although there were no differences in demographic characteristics and psychological well-being at baseline between the 227 women with missing information or who were excluded from the final analysis and the 1503 women included in our final analysis). Women with a higher level of psychological well-being during their pregnancy may be more likely to take part in our study and complete the follow-up investigation. This may affect the generalisability of the study. ${ }^{36}$ Therefore, we are cautious in generalising our results to the urban areas of China. A nationwide study may be necessary in the near future.

Acknowledgements The authors wish to thank the researchers and investigators from the eight hospitals who participated in the distribution and collection of the questionnaires. We also thank Moneeza Walji for language editing.

Contributors $\mathrm{JH}$ and LZ were responsible for the study design, analysis of the study and approval of the submitted and final version. LD, WD and TL contributed to the execution and analysis of the study. ZW contributed to revising the paper and approval of the final version.

Funding National Natural Science Foundation of China (81402687, 81673179), the Science and Technology Commission of Shanghai Municipality (15495810500, 14411970900), and the key discipline of Shanghai 3-year program of public health (15GWZK0401).

Competing interests None declared.

Patient consent Obtained.

Ethics approval The study was approved by the Ethics Committees of the Shanghai First Maternity and Infant Hospital, Tongji University School of Medicine (\#2013-09).

Provenance and peer review Not commissioned; externally peer reviewed.

Data sharing statement No additional data are available.

Open Access This is an Open Access article distributed in accordance with the Creative Commons Attribution Non Commercial (CC BY-NC 4.0) license, which permits others to distribute, remix, adapt, build upon this work noncommercially, and license their derivative works on different terms, provided the original work is properly cited and the use is non-commercial. See: http:// creativecommons.org/licenses/by-nc/4.0/

\section{REFERENCES}

1. Gao LL, Chan SW, Sun K. Effects of an interpersonal-psychotherapyoriented childbirth education programme for Chinese first-time childbearing women at 3-month follow up: randomised controlled trial. Int J Nurs Stud 2012;49:274-81.

2. Singla DR, Kumbakumba E, Aboud FE. Effects of a parenting intervention to address maternal psychological wellbeing and child development and growth in rural Uganda: a community-based, cluster randomised trial. Lancet Glob Health 2015;3:e458-69.

3. Luoma I, Tamminen T, Kaukonen $\mathrm{P}$, et al. Longitudinal study of maternal depressive symptoms and child well-being. J Am Acad Child Adolesc Psychiatry 2001;40:1367-74.

4. Jones TL, Prinz RJ. Potential roles of parental self-efficacy in parent and child adjustment: a review. Clin Psychol Rev 2005;25:341-63.

5. Xie $\mathrm{RH}, \mathrm{He} \mathrm{G}$, Liu A, et al. Fetal gender and postpartum depression in a cohort of Chinese women. Soc Sci Med 2007;65:680-4.

6. Xie RH, He G, Koszycki D, et al. Fetal sex, social support, and postpartum depression. Can J Psychiatry 2009;54:750-6.

7. Hudson DB, Elek SM, Fleck CM. First-time mothers' and fathers' transition to parenthood: infant care self-efficacy, parenting satisfaction, and infant sex. Issues Compr Pediatr Nurs $2001 ; 24: 31-43$. 
8. Elek SM, Hudson DB, Bouffard C. Marital and parenting satisfaction and infant care self-efficacy during the transition to parenthood: the effect of infant sex. Issues Compr Pediatr Nurs 2003;26:45-57.

9. Robertson E, Grace S, Wallington T, et al. Antenatal risk factors for postpartum depression: a synthesis of recent literature. Gen Hosp Psychiatry 2004;26:289-95.

10. Chen J, Xie Z, Liu H. Son preference, use of maternal health care and infant mortality in rural China, 1989-2000. Popul Stud (Camb) 2007;61:161-83.

11. Wu Z, Viisainen $\mathrm{K}$, Hemminki E. Determinants of high sex ratio among newborns: a cohort study from rural Anhui province, China Reprod Health Matters 2006;14:172-80.

12. Xie RH, Liao $\mathrm{S}$, Xie $\mathrm{H}$, et al. Infant sex, family support and postpartum depression in a Chinese cohort. J Epidemiol Community Health 2011;65:722-6.

13. $\mathrm{Li} \mathrm{H}, \mathrm{Yi}$ J, Zhang J. Estimating the effect of the one-child policy on the sex ratio imbalance in China: identification based on the difference-in-differences. Demography 2011;48:1535-57.

14. Lee DT, Yip SK, Chiu HF, et al. Detecting postnatal depression in Chinese women. Validation of the Chinese version of the Edinburgh Postnatal Depression Scale. Br J Psychiatry 1998;172:433-7.

15. Fazio AF. A concurrent validational study of the NCHS General Well-Being Schedule. Vital Health Stat 2 1977;1-53.

16. Nakayama T, Toyoda $\mathrm{H}$, Ohno K, et al. Validity, reliability and acceptability of the Japanese version of the General Well-Being Schedule (GWBS). Qual Life Res 2000;9:529-39.

17. Leonardson GR, Daniels MC, Ness FK, et al. Validity and reliability of the general well-being schedule with northern plains American Indians diagnosed with type 2 diabetes mellitus. Psychol Rep 2003;93:49-58.

18. Taylor JE, Poston WS II, Haddock CK, et al. Psychometric characteristics of the General Well-Being Schedule (GWB) with African-American women. Qual Life Res 2003;12:31-9.

19. Poston WS II, Olvera NE, Yanez C, et al. Evaluation of the factor structure and psychometric characteristics of the General Well-Being Schedule (GWB) with Mexican American women. Women Health 1998;27:51-64.

20. Duan R. The application of General Well-Being Schedule in university students. Comptes Rendus Biologies 1996;4:56-7.
21. Lee KJ, Wiest MM, Carlin JB. Statistics for clinicians: an introduction to linear regression. J Paediatr Child Health 2014:50:940-3.

22. Campbell M. Multiple logistic regression models-what are they? Midwifery 2004;20:236-9.

23. Hou L, Li G, Zou L, et al. [Cesarean delivery rate and indications in mainland China: a cross sectional study in 2011]. Zhonghua fu chan ke za zhi 2014;49:728-35.

24. Tian X, Wu J, Li B, et al. [Occurrence of cesarean section and related factors in 40 counties of China from 1978 to 2010]. Zhonghua Yu Fang Yi Xue Za Zhi 2014;48:391-5.

25. Nie JB. Non-medical sex-selective abortion in China: ethical and public policy issues in the context of 40 million missing females. $\mathrm{Br}$ Med Bull 2011;98:7-20.

26. Zhou C, Wang XL, Zhou XD, et al. Son preference and sex-selective abortion in China: informing policy options. Int $J$ Public Health 2012;57:459-65.

27. Rui D. A family-oriented decision-making model for human research in mainland China. J Med Philos 2015;40:400-17.

28. Pei X, Pillai VK. Old age support in China: the role of the state and the family. Int J Aging Hum Dev 1999;49:197-212.

29. Leung JC. Family support for the elderly in China: issues and challenges. J Aging Soc Policy 1997;9:87-101.

30. Gu B. The practice and enlightenment of the two-child policy regime. Pol J Microbiol 2008;32:33-49.

31. Zhu WX, Lu L, Hesketh T. China's excess males, sex selective abortion, and one child policy: analysis of data from 2005 national intercensus survey. BMJ 2009;338:b1211.

32. Tsatsoulis A, Fountoulakis S. The protective role of exercise on stress system dysregulation and comorbidities. Ann NY Acad Sci 2006;1083:196-213.

33. Gong W, Xu DR, Caine ED. Challenges arising from China's two-child policy. Lancet 2016;387:1274.

34. Jolly M, Sebire N, Harris J, et al. The risks associated with pregnancy in women aged 35 years or older. Hum Reprod 2000;15:2433-7.

35. Gu B, Roy K. Sex ratio at birth in China, with reference to other areas in East Asia: what we know. Asia Pac Popul J 1995;10:17-42.

36. Howe CJ, Cole SR, Lau B, et al. Selection bias due to loss to follow up in cohort studies. Epidemiology 2016;27:91-7.

37. Momen-Heravi F. Selection bias. J Am Dent Assoc 2015;146:497-8 